\title{
Discursive Interactions between University Students during a Laboratory Practice Using SDIS-GSEQ
}

\author{
Edgardo Ruiz Carrillo, Patricia Suarez Castillo, Luisa Bravo Sánchez, \\ Samuel Meraz Martinez \\ Facultad de Estudios Superiores Iztacala, Universidad Nacional Autónoma de México, \\ Mexico City, Mexico \\ Email: edgardo@unam.mx
}

Received 30 January 2015; accepted 26 May 2015; published 29 May 2015

Copyright (C) 2015 by authors and Scientific Research Publishing Inc.

This work is licensed under the Creative Commons Attribution International License (CC BY). http://creativecommons.org/licenses/by/4.0/

(c) (7) Open Access

\section{Abstract}

This paper shows the discourse analysis among students during a laboratory practice using the Software SDIS-GSEQ; the cooperation and teamwork among students are analyzed through their discursive participation in order to streamline their learning and performance in a laboratory practice. The study group consisted of students from the second semester of Biology of Facultad de Estudios Superiores Iztacala, in Universidad Nacional Autónoma de México. The process involved the creation of an instrument in which a set of categories were articulated and a verbal subsystem with subcategories was defined based on the discourse; the software SDIS-GSEQ was used and it established the categorical sequences that were present in the interaction of students during the practice. The results show inhibitory and excitatory categories, as well as flows and cycles of discursive interactions, the latter of which is defined as static and dynamic; the results also include complex discursive cycles, from using the text book, which show a lack of understanding of such text book.

\section{Keywords}

Educational Research, Discourse Analysis, Teaching and Learning Process, Knowledge Production

\section{Introduction}

The teaching and learning processes are closely related to the idea that knowledge is built through the participation and negotiation of people in communities or specific social groups, which are reflected in: practices, rules, 
values, beliefs, modes of relationship, and habits, among others.

This kind of group participation includes cooperative learning. Doménech (1999) states that the objectives of the group members are shared and that each individual will achieve its goal only if its peers achieve theirs too; that is, it is not the sum of contributions, but the integration of these in a common task, which makes it more productive than competitive and individualistic learning because it is based upon the natural provisions of this type of learning that spontaneously needs to ask, doubt, affirm, explain, share, etc., and even the members of the group or team must have certain characteristics to achieve a good performance, such as being heterogeneous in terms of the ability to perform the task, although in some cases it produces a distribution of roles, responsibilities, and it does not usually produce a difference in status among its members. Therefore, cooperative learning is characterized by a high level of equality, seeking to overcome certain "gaps" produced in the exclusive application of traditional learning techniques that are more interested in results than processes, in individual responsibilities rather than group responsibilities, in homogeneous groups rather than heterogeneous ones, and in individual leaders instead of shared leaderships.

Gonzalez \& Rosas (2007) say that this learning makes reference to an alternative way of organizing cognitive processes that take place in a teaching-learning situation both inside and outside the classroom. In the specific case of the cooperation that exists in the classrooms, authors such as Johnson, Johnson, \& Holubec (2008) point out that cooperation consists of working together to achieve common goals, and that in a cooperative situation individuals seek to obtain results that are beneficial to them and to the rest of the members of the group. Cooperative learning is the didactic use of small groups in which students work together to maximize their learning and that of others; that is why the discursive styles that take place in a cooperative environment allow people to gain knowledge and obtain a shared learning in order to achieve common objectives.

The conception of learning as a process of building shared knowledge in a community such as a classroom can only be possible through the communication that occurs among the participants of that activity, which involves paying special attention to the explanations and descriptions that students give to their knowledge not only as a source of information, but also as a form of interpersonal reflection.

In cooperative learning situations, the support among peers is much more frequent than in situations of individual or competitive work, which increases the involvement in the task and the motivation of students who have learning difficulties. Cooperative work teaches strategies and cooperation skills in the classroom with classmates that facilitate the realization of learning, improving their school performance and promoting attitudes of respect, tolerance and collaboration (García, Traver, \& Candela, 2001).

The concept cooperative learning refers to a broad and heterogeneous set of structured instruction methods, in which students work together, in groups or teams, helping each other in tasks usually academic (Melero \& Fernandez, 1995). One of the first differences to be established in order to define what we mean by cooperative learning is, as Ovejero (1990) states, the application of the term cooperation to teaching and learning strategies, or the identification of the type of management in the classroom. In this case, it does not refer to the use of cooperative learning techniques, but to the involvement of students in the organization and structuring of the classroom, from a cooperative perspective: It is a kind of management that is collaborative and jointly responsible between teachers and students, or among teachers, parents, and students. This is known as responsible cooperation or cooperative teaching system.

There is some inadequacy in the term group work, since it does not designate the objectives or modes of interaction that must take place in the work itself, or the common point of view about the task, or the cognitive and affective interactions that occur among the different members of the group. Therefore, we don't know if the classroom distribution in small work groups will make students interact with each other, but the nature of this relationship will vary depending on how you structure the group and the activity, and the purposes of such activity in a cooperative way.

The study of the possibilities for students to practice this mediator role in certain circumstances has been emphasized, so does the analysis of the interaction among students as a factor to take into account and generator of the teaching and learning processes (and not as a dysfunctional and avoidable factor). In this line of thought, the most appropriate way of producing disturbances in the cognitive system of students, capable of producing learning, is the one derived from the interaction with their peers.

The different lines of investigation have reached the conclusion of the superiority of cooperative learning on the variables related to the socializing function of school, as well as on learning and academic performance. As evidenced by the extensive review conducted by Johnson, Maruyana, Johnson, Nelson, \& Skon in 1981, even though there is a wide superiority in cooperative learning proposals both individual and competitive, the main 
variables that affect and determine their obvious superiority are not very clear. As Coll et al. (1992) point out, in order to have a better understanding, it is necessary to deepen the analysis of interaction established among the participants in a group of cooperative learning, in the nature of the interaction.

According to this, it is necessary to facilitate the development of shared understandings and support the construction of appropriate discursive forms. These ideas aim to analyze, describe, and categorize the different discursive styles of the students in the practice, on the one hand to outline a theoretical framework that serves to unravel the relationships between the process of knowledge construction and the practice itself, and on the other hand to find a discursive flow that allows to observe the nature of the interaction.

\section{Method}

\subsection{Participants}

The study group consisted of students from the second semester of Biology of Facultad de Estudios Superiores Iztacala, in Universidad Nacional Autónoma de México. The selection of participants was adjusted to admission criteria. The admission criteria were the following: a) to be regular students of the degree in biology, b) to be interested in participating in the study, and c) to be a second semester student and to be studying the theoretical and practical module of biomolecules. Gender 25 men and 15 women, age 21 - 25 years old, college-level education and middle class.

\subsection{Instruments}

As an instrument of registration, and in order to ensure a maximum accuracy of data collection, two cameras and two microphones were used, which were installed in the laboratory of biomolecules of the group. In accordance with the ethical standards approved by the American Psychological Association, the students of the group were aware that they were filmed and they knew where the video cameras were located.

An instrument of observation, as required by the canons of observational methodology, was elaborated accordingly in the form of a system of categories. The development of the instrument, in order to be in accordance with the requirements of completeness and mutual exclusivity (E/ME; Arias \& Pujol, 2003), initially involved the transcription of all verbal and vocal emissions of the participants, which was complemented with incidental annotations extracted from the viewing of the recordings. A process of categorization of the verbal dimension was carried out and it resulted in different versions of the instrument that were progressively adjusted towards the achievement of the congruence between the name and contents of each category and conditions E/ME (Arias $\&$ Pujol, 2003). The result is the following Table 1.

The software SDIS-GSEQ (Bakeman \& Quera, 1996) was used in order to analyze the data obtained in this study of discursive interactions. As its acronym indicates, it brings together two computer developments. On the one hand, the SDIS makes it possible to obtain sequential data from a normalized and general format, and on the other hand, the GSEQ obtains a description and analysis of sequential data. The SDIS-GSEQ relies on an analytical technique developed by Bakeman (Bakeman, 1978; Bakeman \& Gottman, 1986) and by Sacket (1978, 1979, 1987), taking into account the premises in the works of Bakeman \& Dabbs (1976) and the analysis of the sequential data allows to observe IRE and IRF patterns carried out during the practice.

\section{Results}

The information obtained by sequential analysis of delays, allows to see the probability levels $Z$ and $P$, with which the discursive flow of interaction can be interpreted, by selecting the adjusted residue considered excitatory $(Z>1.96)$ or inhibitory $(Z<-1.96)$; the sequential analysis in delay 1 is carried out by the correlation of the immediate data in the sequence; the delay 2 is carried out by ignoring the immediate data of the pattern, thus showing the connection between the first and the third data (see Table 2).

The probability levels in the table show excitatory connections in most of the categories, with the exception of Predud, where it inhibits Recorr $(Z=-2.13, P=\sim-.03)$ to promote Reori $(Z=2.28, P=\sim .02)$ and Reafi $(Z=$ 2.26, $P=\sim .02)$; Reconf inhibits Reafi in delay $1(Z=2-.18, P=\sim .03)$ and delay $2(Z=1.97, P=\sim .05)$ to promote Preconf and Rereint (both with values $Z=2.21, P=\sim .03$ ), and Reord that in delay 2 inhibits Predud $(Z=$ $-1.96, P=\sim .05)$ by promoting Reconf in the sequence $(Z=2.2, P=\sim .03)$.

It is relevant to show the interactions that characterize the discourse during the cooperative work between 
Table 1. Categories of the discursive sequence, with code and definition.

\begin{tabular}{|c|c|c|}
\hline Category & Code & Definition \\
\hline \multicolumn{3}{|l|}{ How students ask } \\
\hline Confirmation & Preconf & A question to clarify an assumption. \\
\hline Doubt & Predud & A question in order to clarify the knowledge that is not very clear. \\
\hline Orientation & Preori & A question oriented to the use or usefulness of any object. \\
\hline Orders & Preord & A question to generate an action from the other. \\
\hline Affirmation & Preafi & A question to confirm an assumption. \\
\hline Using the text & Pretext & A question based on an assumption included in the instructions manual. \\
\hline \multicolumn{3}{|l|}{ How they answer } \\
\hline Repetition & Rerep & To repeat what was said by the other. \\
\hline Guidance & Regui & To answer with the procedure of a task. \\
\hline Doubt & Redud & To answer with the knowledge that is not very clear. \\
\hline Orienting & Reori & To answer with the elements of a task. \\
\hline Orders & Reord & To answer with the demand of the fulfillment of a task. \\
\hline Confirmation & Reconf & To support the statement or explanation of the other. \\
\hline Reinterpretation & Rereint & To rebuild a knowledge. \\
\hline Correction & Recorr & To rectify what was said by the other. \\
\hline Explanation & Reexp & To expand the knowledge of the other. \\
\hline Using the text & Retext & To answer a question using the instructions manual. \\
\hline Denial & Reneg & To deny the statement or explanation of the other. \\
\hline Affirmation & Reafi & To affirm a knowledge. \\
\hline
\end{tabular}

students when communicative patterns are restricted, that is, if a student asks about something that is unknown, the other student will answer with an orientation or affirmation, instead of correcting the doubt; when the student answers with a confirmation, it is likely that after an action, the response will be with a confirmation or reinterpretation, and the response with an affirmation would be constantly impossible; when there is a response with an order, after an action in response, the answer will be with the confirmation of the action instead of doubting the action (Table 2).

\section{Analysis of Results}

By analyzing the probable levels obtained between the categories in delays 1 and 2, and building sequential relationships that occur between them by placing question marks (?) in the relationships of delay 2 where the intermediate category is unknown, it is possible to observe flows and discursive cycles in the laboratory practice between students (see Figures 1-3). The images show flows that range from one category to the other in an unidirectional way (A-B), and other flows that are recursive with each other (discursive cycles), which can be static: where a category repeats itself constantly in the sequence (A-A), and dynamic: where there are correlations between two or more categories (A-B-A-B), or complex cycles, where there is a correlation both static and dynamic (A-A, B-B, A-B-A-B), these types of flow are shown in Figure 1.

The static cycles observed were the following: Recorr-Recorr, Reexp-Reexp, Redud-Redud, Retext-Retext and Pretext-Pretext, while the dynamic cycles were Reexp-Preconf, Retext-Pretext. Preori-Recorr, Preconf-Reconf. The case Retext and Pretext is considered a complex cycle because it is both dynamic and static, so it seems to have a significant permanence due to the fact that it receives feedback from both. 
Table 2. Values $Z$ and $P$ of the sequential analysis of discursive categories in delays 1 to 3 .

\begin{tabular}{|c|c|c|c|}
\hline Given & Conditioned & $Z$-value & $P$-value \\
\hline Preconf & Reexp & 2.39 & $\sim .02$ \\
\hline Predud & Reori & 2.28 & $\sim .02$ \\
\hline Predud & Recorr & -2.13 & $\sim .03$ \\
\hline Predud & Reafi & 2.26 & $\sim .02$ \\
\hline Preori & Recorr & 3.17 & $\sim<.01$ \\
\hline Preord & Redud & 3.35 & $\sim<.01$ \\
\hline Preafi & Reconf & 2.31 & $\sim .02$ \\
\hline Pretext & Retext & 6.32 & $\sim<.01$ \\
\hline Rerep & Retext & 2.38 & $\sim .02$ \\
\hline Regui & Reord & 2.45 & $\sim .01$ \\
\hline Redud & Rerep & 2.32 & $\sim .02$ \\
\hline Redud & Redud & 3.74 & $\sim<.01$ \\
\hline Reori & Reord & 2.66 & $\sim .01$ \\
\hline Reconf & Reafi & -2.18 & $\sim .03$ \\
\hline Rereint & Redud & 3.35 & $\sim<.01$ \\
\hline Recorr & Preori & 1.97 & $\sim .05$ \\
\hline Recorr & Regui & 1.97 & $\sim .05$ \\
\hline Recorr & Recorr & 3.47 & $\sim<.01$ \\
\hline Reexp & Preconf & 2.44 & $\sim .01$ \\
\hline Reexp & Preord & 2.44 & $\sim .01$ \\
\hline Reexp & Reexp & 2.02 & .04 \\
\hline Retext & Pretext & 4.38 & $\sim<.01$ \\
\hline Retext & Retext & 2.22 & $\sim .03$ \\
\hline Reneg & Redud & 2.26 & $\sim .02$ \\
\hline \multicolumn{4}{|c|}{ Delay 2} \\
\hline Preconf & Reconf & 2.15 & $\sim .03$ \\
\hline Preord & Reconf & 2.15 & $\sim .03$ \\
\hline Pretext & Pretext & 6.32 & $\sim<.01$ \\
\hline Pretext & Retext & 2.08 & $\sim .04$ \\
\hline Redud & Rerep & 2.23 & $\sim .03$ \\
\hline Reord & Predud & -1.96 & $\sim .05$ \\
\hline Reord & Reconf & 2.2 & $\sim .03$ \\
\hline Reconf & Preconf & 2.21 & $\sim .03$ \\
\hline Reconf & Rereint & 2.21 & $\sim .03$ \\
\hline Reconf & Reneg & 2.17 & $\sim .03$ \\
\hline Reconf & Reafi & -1.97 & $\sim .05$ \\
\hline Rereint & Redud & 3.32 & $\sim<.01$ \\
\hline Recorr & Recorr & 3.71 & $\sim<.01$ \\
\hline Reexp & Preord & 3.55 & $\sim<.01$ \\
\hline Reexp & Reexp & 2.18 & 0.03 \\
\hline Retext & Retext & 3.57 & $\sim<.01$ \\
\hline Reafi & Reori & 1.97 & $\sim .05$ \\
\hline
\end{tabular}




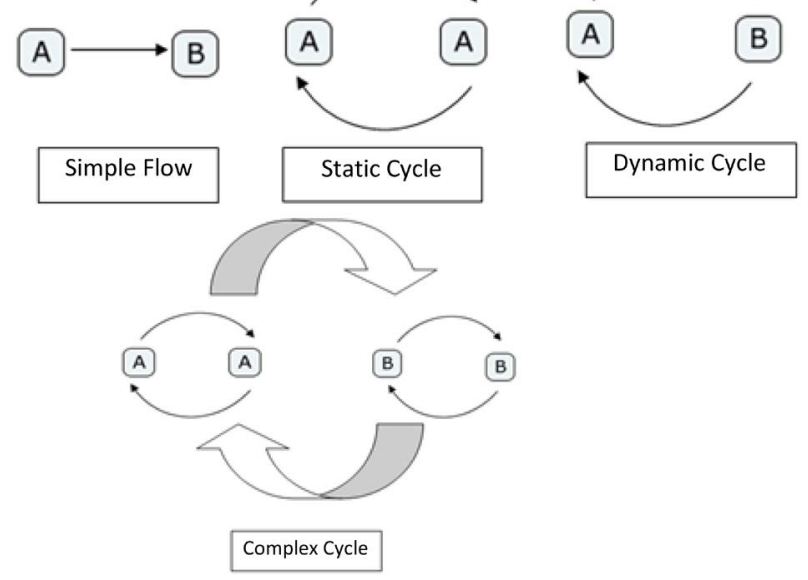

Figure 1. Types of discursive flows.

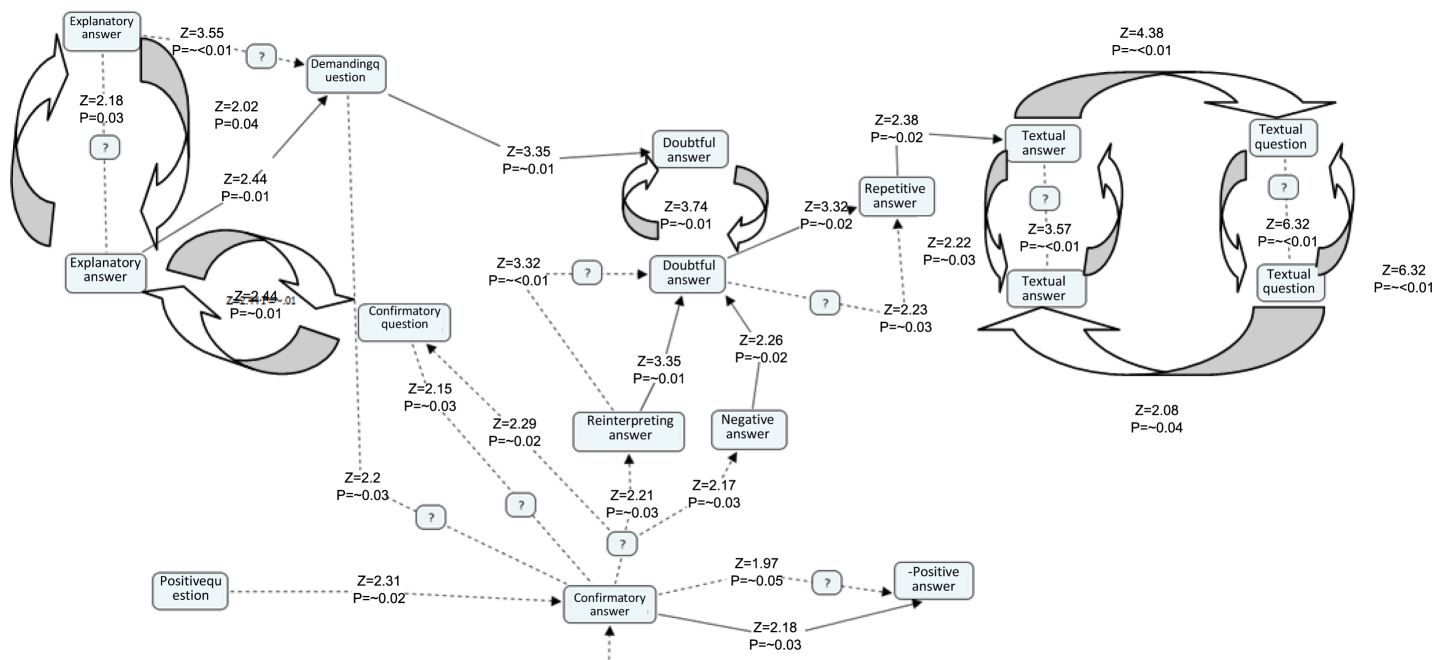

Figure 2. First part of discursive flows between students using delays 1 and 2 .

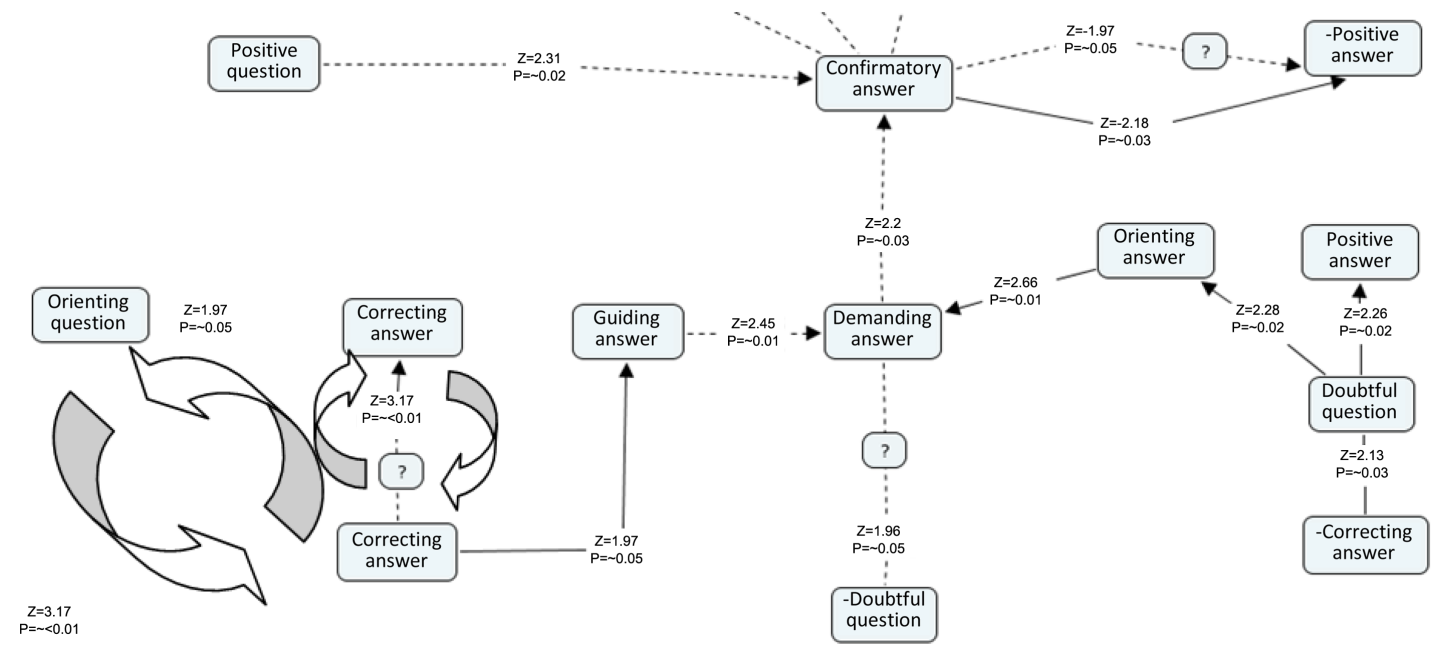

Figure 3. Second part of discursive flows between students using delays 1 and 2 . 
Apart from the cycles and flows shown in the discursive interaction of cooperative work between students, there are other ways to conclude the discursive interaction: The first in Retext-Pretext, where there is a complex cycle, but does not allow the existence of other categories (Figure 1), and the second in Reafi, which does not return to the discourse interaction (Figure 2).

In order to reach the Retext-Pretext cycle, the discursive flow is determined by the cycle Redud-Redud, which leans on Rerep, reaching this conclusive cycle, which may show that after several replies with a doubt and without a clarification, the students end up repeating this dubious response, which leads them to refer to the text, and prevents them from having a discourse where there is a construction of shared knowledge.

\section{Discussion}

The process of the interactive-discursive analysis observed in the laboratory practice through the program SDIS-GSEQ shows interactions that are mostly consistent and that allow a variety of extensive discursive situations.

In general, we observe that in the cycles where the student answers doubting without a clarification, the student continues to repeat this answer at the end by using the text, or manual of practice, thus avoiding the construction of a shared cognitive discourse. We also observe two ways to conclude the discursive interaction: the first in the cycle Retext-Pretext, which inhibits the sequence of other categories, and the second in Reafi, which no longer returns to a discursive cooperative interaction.

Regarding the recurrence to the text as a discursive conclusion strategy between students, it is not characterized by being an active and constructive process of interpretation of meanings involving a series of operations and mental strategies that allow to process the text information and build its meaning to gather new information from the interaction of the ideas obtained from the text and the previous knowledge on the subject, which will result in a process of mental representation of the situation described in the text (van Dijk \& Kintsch, 1983).

By performing tasks involving the use of written material, in our case in the laboratory practice with the activity guide, the students do not reach the construction of representations that generate a cognitive task and that is related to the understanding, explanation, predictions, and other possible actions that depend on the assigned activity (Macías \& Maturano, 2005). An ideal inquisitive subject is an active, self-motivated, creative, inquiring person, who asks deep questions and seeks to answer them (Otero \& Graesser, 2001).

\section{Conclusion}

This can be attributed to several situations specific to the nature of the interaction in this style of practice. The first is the relationship that the student has with the classroom and teacher. The way in which the objective of the laboratory practice is expressed can lead to contradictions within the practice, where the meeting of the objective is more important than understanding the reasons why it is carried out. Another situation belongs to the fact that the members of the practice have assigned roles to carry out the practice, and with this, the knowledge of the same is divided among the students but it is not shared; that is, the practice is successfully accomplished, but without a full understanding and appropriation of its elements. This shows that even within this environment of cooperation generated by the practice in teams, the communication among peers has complications when it seeks to confirm knowledge or performed action.

Therefore, we suggest that it is necessary to find actions that promote the reading comprehension of the text by the students, which reflects an assimilation and understanding of the tasks to perform and intentions of the same, and leads to a practice with a text that is internalized, reinterpreted, explained, understood, and ready to be shared among the members of the team without having to rely so much on the text in a reproductive and mechanical way.

\section{References}

Arias, \& Pujol, E. (2003). Estudio observacional de la interacción en un grupo de psicoterapia de orientación psicoanalitica, a partir del análisis de la conversación. Tesis Doctoral No Publicada, Barcelona: Universitat de Barcelona.

Bakeman, R. (1978). Untangling Streams of Behavior: Sequential Analysis of Observation Data. In G. P. Sackett (Ed.), Observing Behavior, Vol. 2: Data Collection and Analysis Methods (pp. 63-78). Baltimore: University of Park Press.

Bakeman, R., \& Dabbs, J. M. (1976). Social Interaction Observed: Some Approaches to the Analysis of Behavior Streams. 
Personality and Social Psychology Bulletin, 2, 335-345. http://dx.doi.org/10.1177/014616727600200403

Bakeman, R., \& Gottman, J. M. (1986). Observación de la interacción: Introducción al análisis secuencial. Madrid: Morata.

Bakeman, R., \& Quera, V. (1996). Análisis de la interacción. Análisis secuencial con SDIS y GSEQ. Madrid: Ra-Ma.

Coll, C., Colomina, R., Onrubia, J., \& Rochera, M. J. (1992). Actividad conjunta y habla: Una aproximación al estudio de los mecanismos de influencia educativa. Infancia y Aprendizaje, 59-60, 189-232. http://dx.doi.org/10.1080/02103702.1992.10822356

Doménech, F. (1999). Procesos de enseñanza-aprendizaje universitario: Aspectos teóricos y prácticos. Publicación de la Universidad Jaume I, DL.

García, R., Traver, J. A., \& Candela, I. (2001). Aprendizaje Cooperativo. Fundamentos, Características y Técnicas. Madrid: CCS.ICCE.

Gonzalez, N., \& Rosas, M. (2007). El Aprendizaje Cooperativo como estrategia de Enseñanza-Aprendizaje en Psicopedagogía (UC): Repercusiones y valoraciones de los estudiantes. Revista Iberoamericana de Educación, 42, 1-13.

Johnson, D. W., Maruyama, G., Johnson, R., Nelson, O., \& Skon, L. (1981). Effects of Cooperative, Competitive, and Individualistic Goal Structures on Achievement: A Meta-Analysis. Psychological Bulletin, 89, 47-62. http://dx.doi.org/10.1037/0033-2909.89.1.47

Johnson, D., Jonhson, R., \& Holubec, E. (1999). El aprendizaje cooperativo en el aula. Buenos Aires: Paidós.

Macías, A., \& Maturano, C. I. (2005). Las representaciones mentales de los estudiantes a partir de un texto y de una ilustración, referidas a un mismo fenómeno físico. Granada, España: Memorias del VII Congreso Internacional Sobre Investigación en la Didáctica de las Ciencias.

Melero, M. A., \& Fernández, P. (1995). El aprendizaje entre iguales. In P. Fernández, \& M. A. Melero (comps.), La interacción social en contextos educativos. Madrid: Siglo XXI.

Otero, J., \& Graesser, A. (2001). PREG: Elements of a Model of Question Asking. Cognition and Instruction, 19, $143-175$. http://dx.doi.org/10.1207/S1532690XCI1902_01

Ovejero, A. (1990). El aprendizaje cooperativo. Una alternativa eficaz a la enseñanza tradicional. Barcelona: PPU.

Van Dijk, T. A., \& Kintsch, W. (1983). Strategies of Discourse Comprehension. New York: Academic Press. 